\title{
OS CURSOS PRÉ-VESTIBULARES POPULARES ENQUANTO ESPAÇOS EDUCATIVOS E DE FORMAÇÃO DOCENTE: ALGUMAS REFLEXÕES
}

\author{
Douglas Verrangia ${ }^{1}$
}

RESUMO: O presente texto traz uma reflexão pautada na literatura e na experiência de trabalho em Cursinhos Pré-Vestibulares Populares, cursos preparatórios orientados a pessoas das camadas empobrecidas de nossa população. Trata-se de um relato de experiência e, ao mesmo tempo, ensaio teórico/prático no qual argumento, no sentido de ampliar a compreensão, sobre o que entendo por relativo sucesso dos Cursos PréVestibulares Populares (CPVP) em duas questões: enquanto espaço educativo para jovens e adultos de camadas empobrecidas da população; e enquanto espaço de formação inicial de professores/as. Como pano de fundo, procuro olhar para o que tem dado certo nos espaços educativos criados pelos cursinhos populares, a fim de compreender falhas e apontar caminhos para a melhoria da educação formal, pública, de onde vêm os sujeitos que, na busca por implementar seus projetos de vida, chegam a esses espaços de educação popular.

Palavras-chave: Cursinhos Populares; Educação Popular; Práticas Pedagógicas; Formação de Professores.

ABSTRACT: In this paper we present a reflection guided on literature and work experience in popular preparatory courses, geared to people of impoverished strata of our population. This is an experience report and, at the same time, theoretical/practical essay in which, focused on to stimulate a broaden discussion on what I call relative success of Popular Pre-Vestibular Courses (CPVP), on two dimensions: while educational space for youth and adults from impoverished sections of the population; and as an area of teacher's education. As background, I try to look at what has functioned in the educational spaces created by the CPVP, in order to understand flaws and point out ways to improve the formal, public education, where they come from subjects who, in seeking to implement their life projects, reach these spaces of popular education.

Keywords: Popular College Preparatory Courses; Popular Education; Pedagogical Practices; Teachers Education.

Neste texto, procuro refletir sobre a experiência, cerca de quinze anos, de trabalho ativo no Movimento Social ligado à democratização do acesso ao ensino superior público, gratuito e de qualidade, impulsionado pelos chamados Cursinhos Pré-Vestibulares Populares, cursos preparatórios orientados a pessoas das camadas empobrecidas de nossa população. Desta forma, tratase de um relato de experiência, mas também procuro fazer um ensaio teórico/prático sobre esses espaços educativos e sobre suas relações com a

\footnotetext{
${ }^{1}$ Licenciado e bacharel em Ciências Biológicas; Mestre e Doutor em Educação pelo PPGEUFSCar. Professor Adjunto do Dep. de Metodologia de Ensino da Universidade Federal de São Carlos - UFSCar.
} 
escolarização básica pública, muito ligada à questão do acesso, ou não, às universidades públicas no Brasil.

O foco de minha argumentação está - a partir de minha experiência e embasamento teórico - na procura por compreender o relativo sucesso dos Cursos Pré-Vestibulares Populares (CPVP) em duas questões: enquanto espaço educativo para jovens e adultos de camadas empobrecidas da população; e enquanto espaço de formação inicial de professores/as.

Minha ideia é discutir dois aspectos pelos quais os CPVP podem ser considerados espaços educativos de relativo sucesso comparados à escolarização básica pública, mas não só, da qual esses sujeitos são oriundos. São eles a mobilização dos estudantes para a aprendizagem de determinados conteúdos escolares e as positivas relações estabelecidas entre docentes e estudantes. Por outro lado, procuro argumentar também que esses são espaços privilegiados para a formação inicial de professores, quando comparados à formação proporcionada pelas Universidades/Centros de Formação Docente, de dois pontos de vista: da incorporação da necessidade de diversificar estratégias metodológicas; e também do desenvolvimento da dimensão política da docência e do desejo de ser professor. Desta forma, o presente texto procura provocar para a reflexão sobre a importância dos CPVP em nosso país, assim como destacar que eles expressam problemas importantes ligados à escolarização básica e à formação inicial de professores.

A perspectiva adotada, enquanto relato, procura refletir sobre aquilo que escapa, que permanece inexplicado, pelo menos para este autor. Como Orellana (2012, p. 14) explica, analisando a obra de Michel De Certeau, há algo "oculto" no passado, certa estruturação que se opõe ao trabalho histórico, algo já morto e inaccessível. Assim, indo no sentido contrário a esse trabalho dado, morto, procuro refletir um pouco sobre alguns sentidos ainda ocultos para mim, mas de certa forma intuídos, e, espero, que também para muitos leitores preocupados com as questões aqui abordadas.

Alerto que não procuro escrever um texto objetivo, no sentido que anula o subjetivo, ou, que de certa forma, procura esconder que quem escreve sou eu. Ao contrário, adoto postura alinhada a um dos conceitos centrais da filosofia cultural de matriz africana que Mazrui e Ajayi (2010, p. 800) descrevem, no qual se compreende que "sinto, logo penso, logo existo". Dessa 
forma, partindo de visão não cartesiana - "penso, logo existo" - como discutem os autores citados, busco trazer sentimentos e vivências, assim como teorias e noções científicas, para ajudar a compreender o que quero explicitar, o relativo sucesso dos CPVP e suas possíveis causas, assim como possíveis orientações úteis para mudanças positivas, tanto na escola básica quanto na formação inicial de docentes.

\section{TRAJETÓRIA COM CURSINHOS}

As reflexões aqui apresentadas vêm sendo construídas em minha experiência, desde estudante de graduação, como educador em CPVP, muito marcante em minha trajetória profissional e acadêmica. A partir de 1999, atuei como monitor professor/monitor de Biologia em um projeto de extensão universitária, o Curso Pré-Vestibular da Universidade Federal de São Carlos (CPV-UFSCar) por cerca de cinco anos e por mais três como parte da coordenação administrativo-pedagógica do projeto, na cidade de São Carlos, SP. Também fui monitor/professor de um CPVP na mesma cidade, o Cursinho Phoenix (não institucionalizado em uma Universidade) e, a partir de 2010, pude trabalhar no sentido de fundar, com muitas pessoas especiais, coordenando até 2013, um cursinho em Araras, SP, o UFSCurso, ligado ao campus local da UFSCar e à Prefeitura Municipal de Araras.

Na universidade, enquanto estudante do Curso de Ciências Biológicas, pude tomar consciência do impacto de políticas internacionais, neoliberais, sobre a educação no Brasil. Um desses impactos se refere à tentativa de "flexibilização da autonomia universitária", iniciada no governo Fernando Henrique Cardoso (e Paulo Renato de Souza) e sintetizada na PEC 370 A/96. ${ }^{2}$ A comunidade universitária reagiu fortemente a essa proposta que, claramente, ameaçava, e ainda ameaça, desestruturar o ideal de universidade pública, gratuita e de qualidade para todos/as. Foi nesse contexto de discussões que

2 A proposta do governo definia as universidades públicas federais como "entidades administrativas autônomas de regime especial", cujos principais aspectos seriam: Liberdade para contratar e demitir pessoal, bem como para estabelecer o nível de remuneração de seus servidores; regime jurídico especial para seus servidores, de responsabilidade da própria universidade; orçamento definido de forma global, permitida a transferência de recursos entre as rubricas; extensão da autonomia a outras instituições de ensino, não classificadas como universidades. Ver: A Utopia Brasileira (2000), de George Zarur. 
passei a atuar sistematicamente como professor/monitor de Biologia do Curso Pré-Vestibular da UFSCar (CPV-UFSCar), um grande projeto de extensão da Universidade. O CPV-UFSCar tem como intuito contribuir para a democratização do acesso ao ensino superior público, oferecendo preparação para o vestibular a estudantes de escolas públicas oriundos/as de camadas empobrecidas da região em que se situa a UFSCar. Como em muitos CPVP, ao invés de promover revisão de conceitos, como ocorre na maioria dos cursos pré-vestibulares da iniciativa privada, a preocupação centra-se em produzir aprendizagem significativa, muitas vezes, de conceitos nunca vistos anteriormente pelos/as estudantes.

Os processos formativos por mim vividos no contexto desse projeto têm profunda conexão com minha experiência e atuação educativa. É preciso esclarecer que não é a experiência entendida como objeto da percepção "direta da realidade", pois toda experiência é mediada por conhecimentos, valores, ideologias e pela própria reflexão que se faz sobre ela. Refiro-me a essa experiência pensada que integra o indivíduo à sociedade e marca as relações que nela vive. Como Thompson (1981, p. 310) define, a experiência é um processo "que culmina no desenvolvimento da consciência social (...). Ela desempenha uma função integradora, unificando o individual e o estrutural, colocando as pessoas perto daquele todo coerente que têm um sentido". Nesse sentido, pude ampliar e aprofundar minha consciência social trabalhando de forma intensiva no CPV-UFSCar. Pude, nele, aprender sobre: a docência; a relação educador educando; a coordenação administrativa e pedagógica de escolas; a avaliação de práticas pedagógicas; o planejamento e condução de reuniões administrativas e pedagógicas; e até sobre captação e gerenciamento de recursos financeiros.

A experiência como coordenador do projeto foi também central em minha trajetória, pois articulava pesquisa, ensino e extensão e possibilitou desenvolvimento profissional tanto na área de administração escolar quanto na de formação de professores. Essa experiência permitiu a análise científica de meu cotidiano de trabalho como educador, gerando trabalhos de pesquisa. Ao mesmo tempo, pude me orientar também quando passei a lecionar Ciências e Biologia em escolas públicas da rede estadual da região de São Carlos e, posteriormente, assumindo cargo no Ministério da Educação (MEC). Nesses 
contextos, foi possível, em muitos casos, contrastar o trabalho com estudantes no CPVP e em escolas de ensino médio regular, pois muitas os mesmos sujeitos frequentavam ambos os espaços.

Já no UFSCurso, em Araras, vivi uma experiência distinta, pois me coube o processo de fomentar a construção de um CPVP, que teve, inicialmente, financiamento do Programa PROEXT (2010), e com apoio fundamental da prefeitura da cidade de Araras. Esse cursinho, no qual não atuo mais, iniciou suas atividades em 2010, e tem por finalidade:

I - A socialização dos saberes e a emancipação histórica do ser humano, num processo em que, constituindo sua consciência, o homem evolui de ser biológico passivo para ser biográfico ativo, transformando a construção da própria história humana;

II - A autonomia política e pedagógica na condução do projeto, na escolha dos coordenadores e dos professores / monitores do cursinho;

III - Promover o ingresso de jovens de baixo poder aquisitivo nas universidades públicas, com aulas baseadas nos conteúdos programáticos das disciplinas exigidas no Exame Nacional do Ensino Médio (ENEM) e nos principais vestibulares;

IV - Proporcionar uma formação crítica a comunidade possibilitando perspectivas de inclusão social e de formação cidadã;

V - Através da prática docente promover a formação nas áreas de ensino, pesquisa e extensão;

VI - Promover a reflexão e formação continuada da prática docente. (UFSCURSO, 2013).

De forma similar ao relatado anteriormente, pude no UFSCurso constatar como os estudantes se relacionam de forma distinta com o espaço do CPVP em relação à escola regular de onde vêm, geralmente públicas ou privadas com bolsa integral. Ao mesmo tempo, tive experiência singular procurando compreender processos de formação inicial de professores nesse contexto, já que são estudantes dos cursos da UFSCar, em sua maioria absoluta de cursos de licenciatura, que atuam como docentes do Projeto.

\section{CURSINHOS POPULARES: ESPAÇOS FORMATIVOS DE “SUCESSO”}


Como já apontado antes, nesse item procuro explicitar as questões centrais deste texto, inicialmente, a tentativa de propor explicações para uma percepção comum entre educadores de CPVP que atuam, também, em escolas de ensino médio: a qualidade superior do espaço educativo ofertado para jovens e adultos de camadas empobrecidas da população, quando comparado ao das escolas regulares. Em seguida, passo à discussão sobre a potencialidade desses espaços para a formação inicial de professores/as.

\section{ESPAÇO EDUCATIVO PARA JOVENS E ADULTOS DE CAMADAS POPULARES}

Em eventos acadêmicos e também organizados pelo Movimento Social dos Cursinhos Populares, muitas vezes compartilhei a percepção, corroborada por muitos colegas, de que é surpreendente como as relações estabelecidas entre os estudantes e os CPVP são distintas, de forma geral, àquelas que esses mesmos sujeitos estabelecem/estabeleceram com suas escolas de origem. De forma abundante, encontrei percepções de que os estudantes relacionam-se de forma mais positiva, com mais afinco, respeito e com maior reciprocidade com os CPVP do que com as escolas onde concluíram o ensino médio. São dezenas de relatos de situações nas quais professores de CPVP se surpreendem com jovens vistos no ensino médio como desmotivados e apáticos que, nesses projetos, passam a ter protagonismo e a desenvolveremse de forma contundente, tanto do ponto de vista social, relações sociais estabelecidas, quanto cognitivo, aprendizagens realizadas.

Há também um número enorme de relatos dos próprios jovens e adultos estudantes de CPVP, nos quais evidenciam a forma drástica em que mudaram sua relação com a aprendizagem e com o espaço educativo quando passaram a integrar um cursinho popular. Relatam maior dedicação e estímulo para estudar, assim como veem mais sentido em sua atuação enquanto discentes quando comparam à sua experiência pregressa. Percebe-se que, do ponto de vista da mobilização para a aprendizagem de determinados conteúdos escolares, há nesses relatos e na atuação dos mencionados estudantes, a existência de uma forte componente de interesse/desejo para a aprendizagem, em meio a muitas dificuldades e percalços. Os estudantes, de forma geral e 
com exceções importantes, demonstram, nos CPVP, tanto maior disponibilidade para aprender quanto realizam mais ações nesse sentido, mobilizam-se mais para os estudos. Em contraposição, uma série de trabalhos demonstra as enormes dificuldades enfrentadas em relação a esta questão no ensino médio (por exemplo, COSTA, 2006; SPOSITO, 2005). Esses trabalhos mostram como, na perspectiva de jovens estudantes de ensino médio de instituições públicas, há muitas dúvidas em relação ao sentido da escolarização nesse nível e como isso impacta na falta de interesse nos estudos (REIS, 2008).

É importante frisar que, nos projetos com os quais tenho me envolvido, há uma perspectiva adotada de que o espaço dos CPVP não são, apenas, espaços de revisão de conteúdos do ensino médio, mas sim de aprendizagem significativa, para a qual a mobilização é fundamental (CHARLOT, 2001). Dessa forma, os objetivos e abordagens, de forma geral, se assemelham ao ensino médio, que pretende gerar aprendizagens significativas de conceitos, assim como de procedimentos e atitudes, o que não ocorre com muitos cursinhos da iniciativa privada, que se restringem a gerar motivação e a fazer revisões conceituais. Cabe destacar que a mobilização para aprendizagem está sendo entendida aqui na perspectiva da relação com o saber (CHARLOT, 2001). Isto implica em compreender que, nesses espaços educativos populares, mais do que interesse ou motivação, de alguma forma são produzidas determinadas relações com o saber, que geram uma mobilização que não é vista na escolarização no ensino médio, do ponto de vista de nossa experiência de trabalhos científicos na área. Nesse sentido, em muitos casos, essas relações estabelecidas nos CPVP com determinados componentes curriculares (Biologia, Química, Sociologia, etc.) são tão intensas que acabam por alterar ou determinar as escolhas dos estudantes nas carreiras que vão cursar. Cabe mencionar que isso também ocorre no ensino médio regular, mas o que temos percebido é que, nos cursinhos, tal fenômeno é muito frequente.

Poderíamos então, nos perguntar, porque ocorre essa mobilização distinta, no ensino médio e nos CPVP? Quais são as causas dessa diferença identificada por vários colegas do Movimento de Cursinhos Populares? Creio que intensifica essas questões o fato de que, na maioria dos casos, esses espaços não formais contam com menos recursos financeiros e, muitas vezes, 
com corpo docente de menor formação e experiências que as escolas das quais o alunado que recebem é oriundo (geralmente escolas públicas).

Algo que considero central e que deve ser ampliado em trabalhos e discussões posteriores refere-se à distinta posição que ocupam a escolarização básica e os CPVP na constituição e implementação do projeto de vida (HERNÁNDEZ, 2002) desses jovens e adultos. A bibliografia, a seguir referida, tem mostrado que participantes de projetos de educação popular desenvolvem/aprimoram nesses espaços projetos de vida mais claros, definidos e conscientes quanto contrapostos àqueles que não o fazem, isto é, que realizam apenas a educação formal obrigatória, por exemplo. Baseandome em autores como Catão (2007) e Neiva-Silva (2003), penso que os CPVP, enquanto ações mais afeitas à educação popular, têm um papel mais significativo no projeto de vida de jovens e adultos pobres do que a escolarização básica e isso interfere de forma significativa na relação que estabelecem com os saberes abordados e com o trabalho realizado nos CPVP. Sendo ainda mais claro, a escolarização básica de jovens e adultos pobres tem contribuído menos para a elaboração e reflexão sobre o futuro que os CPVP, e isso deve ser um ponto chave a ser pensado. Ao lado da bibliografia apontada, há também relatos de colegas professores de ensino médio em escolas públicas, nos quais se revela que muitas escolas, e consequentemente docentes, sequer mencionam o ensino superior para seus estudantes de ensino médio durante os três anos em que convivem. Na minha experiência orientando e colaborando em trabalhos desenvolvidos por estudantes da UFSCar em escolas públicas da região em que atuamos, pude corroborar essa situação preocupante. Nesses trabalhos, nossos estudantes iam a escolas públicas de ensino médio divulgar: o CPVP; as Universidades Públicas da região; e os diferentes sistemas de ações afirmativas para o ensino superior existentes. Em inúmeras ocasiões, os estudantes da Universidade relatavam o desconhecimento absoluto dos alunos de final de terceiro ano sobre os três temas destacados, o que gerava indignação e também ressaltava a importância desse tipo de ação da Universidade.

É claro que os CPVP, do ponto de vista da relação estudantes-corpo docente e administrativo, não é um mar de rosas. Podemos destacar muitas dificuldades encontradas durante o trabalho: resistências por parte dos alunos 
com relação ao aprofundamento de temas/conceitos; falta de conhecimentos prévios, relativos ao ensino fundamental, que acabam gerando desafios imensos para o trabalho com turmas grandes (sessenta estudantes) frente às exigências de vestibulares; indisciplina, falta de confiança, auto-conceito negativo por parte dos alunos; entre outros. Porém, cabe destacar que tais questões, vão sendo minimizadas por outro elemento que considero importante destacar nesse texto, que também representa um relativo sucesso dos CPVP frente à escolarização formal: as positivas relações estabelecidas entre alunos e professores.

Todos os colegas com os quais tenho contato relatam o mesmo: que as relações estabelecidas entre docentes e estudantes são muito mais amistosas e positivas nos CPVP do que na escolarização básica prévia desses alunos, com raras, mas importantes, exceções. Nesse sentido, os cursinhos populares têm podido propiciar o estabelecimento de relações de afetividade, de respeito, de companheirismo e amizade entre professores-estudantes. Nos processos educativos que tenho vivido, com muitas pessoas, em CPVP, é notória a percepção de que os processos de aprendizagem não são, sozinhos, o centro do trabalho educativo. As relações humanas - pessoais, interpessoais, sociais - estão também no centro e são fundamentais para o trabalho, questão sempre relatada pelos estudantes desse tipo de projeto. Relatos de jovens e adultos sobre como os professores de CPVP são mais amigos, mais próximos, preocupados, disponíveis são frequentes em conversas e encontros de educadores desse tipo de projeto. Essa percepção é corroborada por trabalhos como o de Reis (2008, p.11), que analisando a visão de jovens sobre o trabalho educativo vivido em um projeto de educação popular, relata:

\footnotetext{
Portanto, apreendem [os estudantes que] os processos educativos tais como a convivência, o diálogo, a amizade, a autonomia e criatividade, os debates, o olhar crítico, o trabalho em grupo, a multiplicação de conhecimentos, a participação, entre outros vivenciados na ONG como significativos para a melhoria da qualidade da educação escolar pública porque propiciam esse contexto prazeroso, relacionado com suas realidades, de aprender uns-com-os-outros.
}

Voltando à nossa experiência, essa relação é apontada por estudantes egressos de CPVP que passam a integrar o ensino superior, que sentem falta 
do espaço do cursinho e questionam-se sobre as diferenças sentidas na escolarização prévia, no ensino médio, e também, a Universidade. Essa questão é tão central que muitos egressos de CPVP, quando ingressam nas Universidades, vão procurar projetos semelhantes e neles se integram, fechando um ciclo de formação e de solidariedade. Muitos se veem impelidos a "retribuir" o trabalho, outros relatam atuar porque serão professores no futuro, mas o clima desse tipo de projeto é sempre mencionado como causa da participação.

Durante o processo de escritura deste texto, num intervalo que tomei para um café, encontrei uma ex-aluna do CPV-UFSCar, que, na época, trabalhava como empregada doméstica para custear 0 transporte para 0 projeto. Ela me chamou pelo nome, eu também lembrava o seu, e nosso último encontro havia sido em 1999. No encontro, me informou que cursa o Doutorado em Ciências Políticas e, numa dimensão mais afetiva, nosso abraço amistoso concretiza o que, aqui, escrevo de forma menos rica.

Há, certamente, outras questões centrais ligadas às relações entre estes estudantes e os CPVP que poderiam ser discutidas aqui, como, por exemplo, a convivência em salas de aulas cuja diversidade geracional é marcante. Nos CPVP, convivem, muitas vezes, adolescentes, jovens, adultos e idosos, em situação de equidade de função/ação, são todos estudantes. No mesmo sentido, muitos desses cursinhos têm gestões nas quais o corpo discente tem participação ativa e efetivamente democrática, sendo protagonistas centrais nos processos decisórios. Certamente, estas questões interfere nas relações estabelecidas e, a meu ver, contribuem para a positividade desses espaços educativos. Outra questão que gostaria de mencionar é o que Thompson (1981) chama de despertar da consciência social. Porém, não é possível aprofundar nelas devido ao espaço e escopo escolhido para o texto. Apenas pontuo que, para muitos jovens e adultos alunos dos CPVP nos quais trabalhei, é nesse espaço que ocorre uma formação que os leva a compreender melhor as relações sociais, de: classe; gênero; e raça-etnia. Ressalto ainda que esses projetos discutem de forma aberta, em atividades específicas e curriculares, tais temáticas. Essa formação impacta de forma profunda na construção da identidade dessas pessoas, e, quase sempre, esses sujeitos questionam porque tais questões não foram abordadas na escolarização formal. Dessa 
forma, esses espaços suprem uma demanda educacional extremamente relevante, pensando em uma educação para a vivência de cidadania plena e na contribuição para o desenvolvimento de uma identidade positiva, ligada a pertencimentos de várias dimensões. Dentre eles, o desenvolvimento ou valorização do pertencimento étnico-racial e de classe social se destacam muito, e isso tem, inclusive, impactos nas universidades, quando lá chegam estes estudantes, que passam a fazer demandas específicas, já refletidas. Ao mesmo tempo, essas demandas e expectativas - por exemplo, de conhecer mais sobre história e cultura africanas e afro-brasileiras ou sobre os movimentos sociais - são, muitas vezes, frustradas. No mesmo sentido, os relatos apontam que a temática da orientação e diversidade sexual foi discutida por estes estudantes pela primeira vez no contexto dos CPVP, pelo menos de forma menos estereotipada e/ou moralizante, tendo tido impacto positivo na constituição das identidades desses sujeitos.

\section{FORMAÇÃO INICIAL DE PROFESSORES}

Como já anunciado, os CPVP são espaços privilegiados para a formação inicial de professores, e, inclusive, de relativo sucesso quando comparados à formação proporcionada pelas Universidades/Centros de formação docente. Na minha experiência tenho acompanhado a formação de muitos/as professores/as no contexto desse tipo de projeto ligado à Universidade. Nem sempre os estudantes universitários ligados a cursinhos fazem cursos de licenciatura e, nesses casos, não se espera que o trabalho resulte na formação docente. Porém, mesmo com esses estudantes, o cursinho tem um impacto tão forte que muitos acabam orientando seu trabalho profissional para a docência. No caso dos egressos de cursos de licenciatura, essa questão é muito mais evidente e os CPVP têm sido espaços muito importantes para formar professores melhor preparados e, mais importante, que efetivamente desejem exercer a docência.

Um dos aspectos que, identifico, como uma contribuição dos CPVP para a formação docente é a incorporação, pelos professores em formação da necessidade de diversificar estratégias metodológicas. Algo abundante na literatura em Educação e Formação de Professores é a, ainda muito presente, 
ausência de uma diversidade significativa de estratégias de ensino no ensino médio regular. Isto é, na maioria das escolas ainda prevalece como atividade central a exposição de conteúdos conceituais (VASCONCELOS, 1996; TEIXEIRA, 2003).

Como docente do magistério superior e equipe de coordenação de um cursinho, pude ministrar disciplinas que lidam diretamente com essa questão. Nessas experiências, pude verificar e discutir, com os professores do projeto (ao mesmo tempo estudantes) como o trabalho no cursinho gera, devido à incompatibilidade entre dimensão abstrata (rever conteúdos) e concreta (ausência de conhecimentos básicos) uma série de contradições a serem superadas. Uma delas refere-se à necessidade de repensar metodologias/estratégias de ensino, frente à constatação de que o objetivo do trabalho é outro, diferente da primeira concepção, a revisão. Nesse sentido, os professores em formação questionam-se fortemente acerca de como ensinar, e não revisar, conteúdos e passam por um processo de reflexão sobre seu trabalho frente às condições concretas dos alunos: diversidade e, muitas vezes, escassez, de conhecimentos cobrados em processos seletivos. Essa questão aparece, por exemplo, dentre os quatro objetivos que os estudantes/professores em formação atuantes no UFSCurso, colocam como objetivos do projeto:

\footnotetext{
A Mobilização de recursos humanos e materiais que auxiliem o Cursinho Popular UFSCurso no exercício de suas funções, aprovisionando condições que permitam:

[...] d) Auxiliar os estudantes do ensino médio na superação dos déficits educacionais, tornando-os competitivos para os processos de seleção universitários (UFSCURSO, 2013).
}

Essa é uma constante em projetos deste tipo e é revelador que a organização responsável por esta publicação se denomine Centro de Investigações de Metodologias Educacionais Alternativas Conexão (grifo meu).

Por outro lado, vivencio cotidianamente em meu trabalho de professor do ensino superior em cursos de licenciatura a necessidade de sensibilizar os professores em formação, estudantes universitários, sobre o papel da diversificação das formas de atuação pedagógica. Percebo ainda que, dentre egressos das licenciaturas que não vivenciam a ação pedagógica em projetos 
como os aqui discutidos, a percepção dessa necessidade surge tardiamente, no trabalho já como contratados ou efetivos nas redes de ensino. É claro que há também aqueles que não incorporam tal necessidade e passam a se frustrar cotidianamente com as falhas de suas investidas, interpretadas, quase sempre, como culpa dos alunos, no sentido que Aquino (1998) aborda em artigo sobre a indisciplina na sala de aula.

Ao contrário da situação apontada, estudantes que trabalham em CPVP demandam tal discussão ainda na graduação, o que torna muito mais fácil a incorporação desta noção nos futuros professores. Essa questão pode tornarse tão central a ponto de que todo o projeto pedagógico do CPVP se realiza de forma a contemplar essa diversidade. Por exemplo, no CPV UFSCar vivenciei a existência de currículos distintos:

[...] turmas de um ano e de dois anos. As turmas de um ano costumavam ter as disciplinas tradicionais do ensino médio focando nos conteúdos mais cobrados nos vestibulares/Enem. As turmas de dois anos, no primeiro ano, tinham disciplinas diferenciadas que visavam preparar os alunos não somente para maior compreensão dos conteúdos do ensino médio, mas para, sobretudo, compreenderem melhor os fenômenos socioculturais e políticos, o que lhes permite agir de maneira mais crítica na sociedade. Depois, no segundo ano, os alunos entravam em contato com o conteúdo tradicional (UFSCar, 2013).

Sendo assim, no cursinho mencionado a necessidade de diversificar o processo de ensino gerou a separação de turmas com currículos diferenciados transcorridos em tempos diferenciados. Essa é uma constante nos CPVP e a necessidade de considerar a diversidade existente no alunado gera desde ações tímidas até estruturas curriculares inovadoras, democráticas e que lidam com temáticas socioculturais ainda distantes das escolas formais: questões identitárias; desigualdade social; organização comunitária; cooperativismo e associativismo; solidariedade de classe; entre outras.

A formação inicial de professores no contexto dos CPVP também tem evidenciado um sucesso relativamente alto em desenvolver ou aprofundar, nos futuros docentes, uma dimensão política da docência. Como Paulo Freire ensinou, a Educação é a prática da libertação, desvelamento do mundo, 
tomada de consciência das relações históricas, políticas e culturais estabelecidas na sociedade. Ao mesmo tempo, ele nos alertou para a existência, no sentido contrário ao mencionado, de uma educação bancária, prática social contrária à libertadora. Nas palavras do educador, na educação bancária:

[...] o educador aparece como seu agente irredutível, como seu sujeito real, cuja tarefa indeclinável é 'encher' os educandos com os conteúdos de sua narração. Conteúdos que são apenas retalhos da realidade, desvinculados da totalidade em que se engendram e em cujo contexto adquirem sentido (FREIRE, 1978).

A educação bancária, descrita por Freire, conduz os educandos à memorização mecânica de conteúdos narrados, transformando-os em recipientes, depósitos, destituindo-os de seu caráter de sujeito social. Infelizmente, como muitos autores ainda mostram, a educação bancária ainda é comum nas escolas regulares em nosso país, e no ensino médio, mais ainda, nas diversas regiões do país e nos diferentes componentes curriculares (GENTILI, 2007; PATTO, 2005; MALDANER e FERNANDES, 2011).

É interessante, então, pensar que, do ponto de vista histórico, os cursinhos populares são oriundos de prática correlata, os cursinhos prévestibulares da iniciativa privada, que, quase sempre, tem a educação bancária como norma (listas enormes de conteúdos conceituais, fórmulas sem sentido, memorização de tabelas, leitura de resumos de livros, etc.). Porém, os cursinhos populares procuram afastar-se dessas práticas, gerando gestões educativas dialógicas e práticas democráticas de atuação docente. Mais do que isso, se convertem em espaços de educação popular, no sentido freiriano, em que os professores assumem seu papel enquanto seres humanos políticos e ideológicos, mostrando sua verdadeira função social. Esse desejo de educação popular, por exemplo, pode ser visto na própria forma como se definem e denominam vários projetos: Cursinho Paulo Freire, Coletivo Malungo, Zumbi dos Palmares, Steve Biko, Hannah Arendt, entre muitos outros. Essa intenção fica clara também quando observamos os objetivos desses projetos, como aparece, por exemplo, no estatuto do UFSCurso: 
A Mobilização de recursos humanos e materiais que auxiliem o Cursinho Popular UFSCurso no exercício de suas funções, aprovisionando condições que permitam:

a) Defender e promover, de fato, o direito à educação pública, gratuita e de qualidade;

b) Construir uma educação como prática da liberdade, através do desenvolvimento de atividades e pesquisas interdisciplinares que visem $o$ aprendizado, a criação e a difusão de conhecimentos científicos e artísticos, necessários à autonomia humana social política e cultural (UFSCURSO, 2013).

Percebe-se claramente a dimensão política da docência nesse tipo de documento, o que, certamente, interfere na formação profissional desses educadores. A professora Dulce, discutindo o impacto dos Cursinhos Populares na formação de professores, corrobora nossa visão e coloca uma questão central:

O fato de passar por um cursinho popular, desde que ele possua um projeto mais democrático, alarga a visão de mundo do professor. Mesmo que ele vá à universidade ou vá trabalhar em uma escola particular, ele vai com outra perspectiva. Ele já não vai com aquela visão bancária da educação. (WHITAKER, 2013, p. 10).

Cabe destacar que não é possível afirmar que todos os cursinhos populares levam a essa formação mais democrática. Porém, minha experiência está calcada em projetos de gestão democrática e nos quais têm sido possível verificar formação de professores com consciência das desigualdades sociais e das relações desiguais derivadas destas em nosso país. Por exemplo, no período em que trabalhei na coordenação do CPV UFSCar, em 2001, enviamos uma proposta inovadora de currículo para o programa Diversidade na Universidade, que foi aprovada e financiou parte dos custos do projeto na época. Assim, antes da promulgação da Lei 10.639/03 - que instituiu a obrigatoriedade do ensino de história e cultura africana e afro-brasileira nas redes de Educação Básica - esse cursinho já vem ministrando uma disciplina de Africanidades, ademais de outras ligadas à formação política e cidadania. Algo semelhante pode ser visto em muitíssimos cursinhos populares, que discutem, há muito tempo, esse tipo de questão (ANDRADE, 2002). Desta forma, os cursinhos vêm dando formação específica para a compreensão do 
sexismo, do racismo, da exclusão econômica e dos impactos destes nas relações sociais e nas desigualdades, assim como para que esses futuros docentes possam exercer prática condizente com os direitos humanos e a justiça social.

Finalizo este tópico destacando os CPVP como espaços muito relevantes para a formação de professores que possam compreender os diferentes aspectos da dimensão política da docência e, efetivamente, engajarem-se em processos educativos consonantes com as demandas por mudanças sociais que vivemos, algo que não tem sido alcançado pela formação universitária no Brasil, haja visto os dados da literatura contemporânea. Creio que seja também relevante mencionar que os CPVP são, no contexto no qual atuo, responsáveis pelo despertar do desejo de ser professor em muitos estudantes de graduação, algo que, devido à situação atual, é cada vez mais raro fora desses espaços. Essa questão deve ser mais bem discutida em outro texto, com a devida atenção que merece, mas apenas pontuo que programas como o PIBID $^{3}$ têm mostrado formas alternativas de formação docente mais alinhadas às demandas contemporâneas e que despertam mais desejo e conexão com a carreira, algo que os CPVP vêm fazendo há, pelo menos, vinte anos.

\section{POR FIM...}

Neste texto procurei fazer uma provocação com vistas à ampliação da discussão acerca da importância dos Cursinhos Populares enquanto espaços educacionais frutíferos e complexos. Procurei apresentar argumentos na busca por compreender relações causais para o que chamei, propositadamente, de sucesso desses espaços, frente à escolarização formal e à formação docente tradicionalmente realizada em nosso país.

Espero, com este texto, estimular que outras pessoas, como eu interessadas na questão da democratização do acesso à universidade pública, gratuita e de qualidade e na melhoria da educação básica em nosso país, escrevam, a partir de outras experiências e/ou referenciais sobre os CPVP. De

3 Programa Institucional de Bolsa de Iniciação à Docência. Ver: <http://www.capes.gov.br/educacao-basica/capespibid>. 
nenhuma forma procurei fazer uma crítica destrutiva acerca da escolarização básica pública, que defendo e em prol da qual dedico esforços cotidianamente, muito menos acerca da formação docente na Universidade, meu trabalho diário. Na verdade, acredito que a análise séria e sistemática de espaços de educação não formal, como já apontou claramente Gohn (GOHN, 2006), pode ajudar muito a reformulação dos espaços formais. Em um texto interessante e esclarecedor, a professora Dulce Whitaker ponderou:

O cursinho é o maior atestado da falência da escola, tanto pública como privada. O aluno da escola privada também precisa fazer cursinho para passar no vestibular. Então, não é a escola pública que é pior ou a particular melhor: a escola particular também vende um produto que ela não entrega (WHITAKER, 2013).

Não estou certo se os cursinhos são o maior atestado de falência do ensino médio, mas tenho absoluta clareza de que esses espaços têm muito a contribuir para compreender falhas e aponta caminhos para a melhoria que necessitamos e almejamos. Nesse sentido, olhar para o que tem dado certo nos espaços dos cursinhos populares, ou de práticas de educação popular não formal, tem sido uma estratégia que considero interessante e na qual temos apostado tempo e esforços. Cabe a nós, pessoas interessadas na transformação, trilhar caminhos diversificados e, quem sabe, nos encontraremos, em espaços mais dignos, ricos e justos de formação humana.

\section{REFERÊNCIAS BIBLIOGRÁFICAS}

ANDRADE, Rosa Maria T. Cor e Gen/e/te/ética. In: ANDRADE, Rosa Maria T.; FONSECA, Eduardo F. Aprovados! Cursinho pré-vestibular e população negra. São Paulo: Selo Negro Edições, 2002. p. 119-132.

AQUINO, J. G. A indisciplina e a escola atual. Rev. Fac. Educ., São Paulo, v.24, n.2, 1998.

CATÃO, M. F. M. Projeto de Vida em Construção na exclusão Inserção Social. João Pessoa: UFPB, Ed. Universitária. 2001. Apud: SEQUEIRA, M. V. M.; CATÃO, M. F. F. M. Adolescentes em processo de exclusão e a construção do projeto de vida. Anais do V Jornada Internacional e III Conferência Brasileira sobre Representações Sociais. Brasília: 1 CD-ROOM, 2007. 
CHARLOT, Bernard (Org.) Os jovens e o saber: perspectivas mundiais. Porto Alegre: Ed. Artmed, 2001.

COSTA, Antônio Carlos da. Protagonismo Juvenil: adolescência, juventude e participação democrática. 2.ed. São Paulo: FTD; Salvador: Fundação Odebrecht, 2006.

FREIRE, Paulo. Pedagogia do Oprimido. Rio de Janeiro: Ed. Paz e Terra, 1978.

GENTILI, P. Adeus à escola pública. In: GENTILI, P. Pedagogia da exclusão: Crítica ao neoliberalismo em educação. Petrópolis, RJ: Vozes, 2007. 228253.

MALDANER, Jair José; FERNANDES, Isabella Alves. Os resquícios da concepção bancária de educação no ensino da matemática: um relato a partir das experiências do PIBID IFTo Campus Palmas. V Colóquio Educação e Contemporaneidade, Sergipe, 2011.

HERNÁNDEZ, Ovidio D’Angelo. Ética y Sociedad: vol. 2. La Habana: Ed. Félis Varela, 2002.

MAZRUI, A. A.; AJAYI, J. F. A. Tendências da filosofia e da ciência na África. In: MAZRUI, A.; WONDJI, C. (Ed.). História Geral da África: África desde 1935. Brasília: UNESCO, 2010. (tomo VIII)

NEIVA-SILVA, L. Expectativas futuras de adolescentes em situação de rua: um estudo autofotográfico. 2003, 176 f. Dissertação (Mestrado em Psicologia). Universidade Federal do Rio Grande do Sul, Porto Alegre, 2003.

ORELLANA, Rodrigo Castro. Michel De Certeau: História e Ficção. Princípio: Revista de Filosofia, Natal (RN), v. 19, n. 31, p. 5-27, Jan./Jun. 2012.

PATTO, M. Produção do fracasso escolar: a histórias de submissão e rebeldia. São Paulo: Casa do Psicólogo, 2005.

REIS, Denise Maria. Educação escolar pública na perspectiva de jovens protagonistas participantes de uma ONG. Simpósio de Pós-Graduação do II Congresso Internacional de Pedagogia Social, 2008.

SPOSITO, Marília. Algumas reflexões e muitas indagações sobre as relações entre juventude e escola no Brasil. In: ABRAMO, H., BRANCO, P. P. M. Retratos da Juventude Brasileira: análises de uma pesquisa nacional. São Paulo: Fundação Perseu Abramo, 2005.

TEIXEIRA, P. M. M. Educação Científica e Movimento C.T.S. no quadro das tendências pedagógicas no Brasil. Revista Brasileira de Pesquisa em Educação em Ciências, São Paulo, v. 3, n. 1, p. 88-102, 2003. 
THOMPSON, Edward P. A miséria da teoria: ou um planetário de erros. Rio de Janeiro: Zahar Editores, 1981.

UFSCAR, 2013. Curso Pré-Vestibular. Acesso em: 02/12/2013. Disponível em: $<$ http://www2.ufscar.br/comunidade/cursinhoprevestibular.php $>$.

UFSCURSO, 2013. Estatuto do Curso Pré-Universitário Popular UFSCurso. Divulgação restrita.

VASCONCELOS, I. A metodologia enquanto ato político da prática educativa. In: CANDAU, V. M. (Org.) Rumo a uma nova didática. 8. ed. Petrópolis: Vozes, 1996. p. 97-104.

WHITAKER, D. Educação, Sociologia e Cursinhos Populares: entrevista com Dulce Whitaker. Cadernos CIMEAC, Ribeirão Preto, v. 3, n. 1, 2013.

ZARUR, G. A utopia brasileira. Brasília, DF: Abapé, 2000. 